\title{
The Prevalence and Characteristics of Patients Diagnosed with Osteogenesis Imperfecta at the Zambia Italian Orthopedics Hospital Community Based Rehabilitation Project
}

\author{
Stella Kabengo, Esther Munalula-Nkandu, James C. Munthali, Loveness A. Nkhata*, \\ Hastings Shula
}

Department of Physiotherapy, School of Medicine, University of Zambia, Lusaka, Zambia

Email address:

Lnkhata@yahoo.com (L. A. Nkhata)

\section{To cite this article:}

Stella Kabengo, Esther Munalula-Nkandu, James C. Munthali, Loveness A. Nkhata, Hastings Shula. The Prevalence and Characteristics of Patients Diagnosed with Osteogenesis Imperfecta at the Zambia Italian Orthopedics Hospital Community Based Rehabilitation Project. Science Journal of Public Health. Vol. 3, No. 5, 2015, pp. 804-807. doi: 10.11648/j.sjph.20150305.40

\begin{abstract}
Introduction: Osteogenesis Imperfecta is a rare condition that can be very disabling. It is an inherited disease of the bones, which is characterized by fragility that causes affected individuals to have recurrent fractures that subsequently lead to pain, deformity and disability. The aim of the study was to determine the prevalence of Osteogenesis Imperfecta and identify the common deformities and treatment methods used in managing affected individuals at the Zambia Italian Orthopedics Hospital. Methods: This was a retrospective cross sectional survey. A data capture sheet was used to collect data from records and descriptive trend analysis was done in excel. Results: We identified 18 patients with Osteogenesis Imperfecta out of 8250. The age range was 1 to 17 years. Eighty-three percent $(n=15)$ of these patients had deformities which included; bowed lower limbs, scoliosis and other related complications. All the patients underwent surgery at one point in time and received physiotherapy. Conclusion: The prevalence of Osteogenesis Imperfecta at the Zambia Italian Orthopaedics Hospital Community Based Rehabilitation Project is low. Surgery is the most commonly used method of treatment coupled with physiotherapy. Though uncommon, the condition is expensive to manage for both the institution and affected individuals' families. This is as a result of repeated surgeries and prolonged physiotherapy.
\end{abstract}

Keywords: Osteogenesis Imperfecta, Surgery, Physiotherapy, Orthopedics, Disability, Rehabilitation

\section{Introduction}

Osteogenesis Imperfecta (OI) is a rare condition that can be very disabling for affected individuals. It is an inherited disease of the bones, which is characterized by fragility that causes recurrent fractures that subsequently lead to pain, deformity and disability. It is present aproximately in 1 out of 20,000 individuals including people diagnosed after birth in developed countries [1,2]. Marini [3] reports that there are no preferential distributions of OI by gender, race, or ethnic group. According to Newacheck [4], the brittle bone disease is found in all races, and the incidence in the developing world is thought to be similar to that in Western Europe. In addition, the symptoms for OI vary from person to person and can range from mild to severe. Marini and Fine [5] report that people with OI are born with defective connective tissue, or the inability to produce it. This maybe because of a deficiency in type 1 collagen as a result of mutations in the COL1A1, COL1A2, CRTAP, and LEPRE1 genes. Affected individuals could therefore, have a few or several fractures in a lifetime. While there is no cure the symptoms patients present with are managed using medication, physiotherapy, surgery and mobility aids such as; wheelchairs and braces to decrease the number of fractures and disabilities. Affected individuals exhibit an array of associated features, which include short stature, macrocephaly, blue sclera, dentinogenesis imperfecta, hearing loss, ligament laxity and neurological and pulmonary complications $[5,6]$. Further, most individuals with OI have significant physical handicaps and often, severe lower limb deformities due to recurrent fractures that significantly hamper ambulation. Wilson [7] describes the condition as the most common osteoporotic 
syndrome in children that exhibits a broad range of clinical severity ranging from multiple fractures in utero to perinatal deaths. A few studies have reported the prevalence of OI and have focussed on the outcomes of different treatment methods used in OI $[8,9]$. Though the number of children with OI reported in most studies is low, the sequelae of this disease, is devastating because of musculoskeletal deformities [4, 5, 6]. In Zambia, the lack of adequate and precise data on OI formed the rationale for this study. The aim was to determine the prevalence and characteristics of patients diagnosed with OI at the Zambia Italian Orthopedics Hospital Community Based Rehabilitation Project (ZIOHCBR). In addition, the study set to identify the common deformities and treatment methods used in managing affected individuals during the 2007 to 2011 period.

\section{Methods}

We conducted a retrospective cross sectional survey and utilized a data capture sheet in excel to collect information from the 2007-2011 records. The study clearance and approval was sought from the Biomedical Research Ethics Committee of the University of Zambia (UNZABREC). Descriptive trend analysis was done using the statistical package for social sciences (SPSS) version 16.0 for windows and summarized using descriptive statistics. The significance cutoff point was set at $5 \%$ and p-values were used to draw conclusions.

\section{Results}

Out of 8250 patient records reviewed $0.22 \%(n=18)$ had OI. Of the $18,67 \%(n=12)$ were females. The mean age distribution was 8.67 ( $\mathrm{SD}=0.857)$. Among the patients, $44.4 \%(n=8)$ were in the $6-10$ age range and attained primary school education. Figure 1 gives an illustration of the level of patient education.

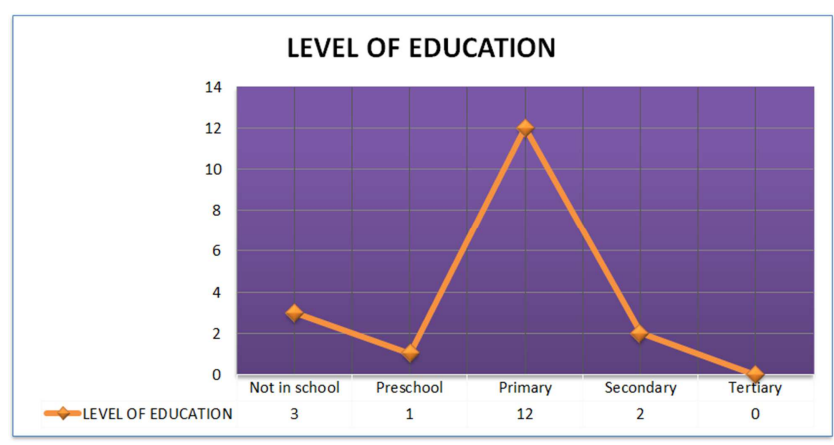

Figure 1. Patient's Educational levels.

\section{Distribution of Affected Body Parts of Osteogenesis Imperfecta and Musculoskeletal Deformities}

Majority of the patients $83.3 \%(n=15)$ had deformities which affected the musculoskeletal, neurological or respiratory systems. Bowed lower limbs were the most commonly identified deformities $73.3 \%(n=11)$, followed by scoliosis $20 \%(n=3)$. Furthermore, 11\% $(n=2)$ patients with deformities also had hydrocephalus and pneumonia complications. Out of the 15 patients with deformities, $73.3 \%$ had bowed lower limbs.

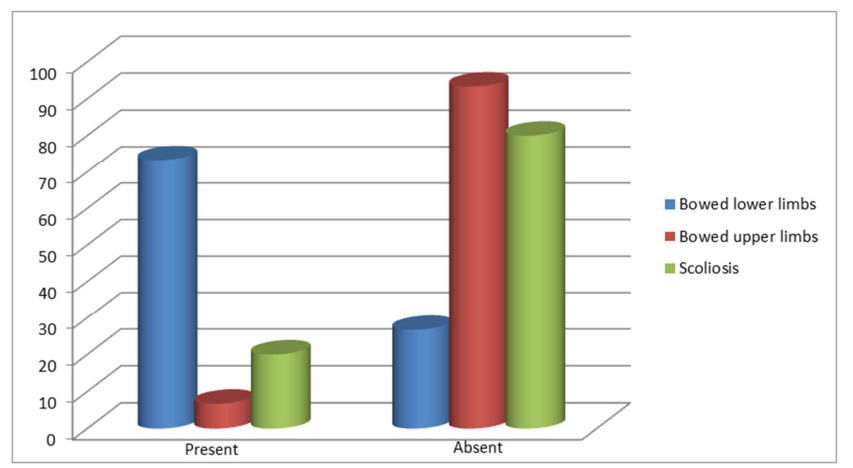

Figure 2. The distribution of musculoskeletal deformities.

\section{Association Between Deformities, Age and Gender}

There was no statistically significant association between deformity, age and gender in this study (Table 1).

Table 1. Relationship between Deformities and Age.

\begin{tabular}{|c|c|c|c|c|c|}
\hline \multirow[t]{2}{*}{ Age range } & \multicolumn{2}{|c|}{$\begin{array}{l}\text { Number of patients with } \\
\text { deformities }\end{array}$} & \multirow[t]{2}{*}{ Total } & \multirow[t]{2}{*}{$\mathrm{Chi}^{2}{ }^{2}$} & \multirow[t]{2}{*}{ P-value } \\
\hline & Yes & No & & & \\
\hline $1-5$ years & 3 & 1 & 4 & \multirow{5}{*}{1.800} & \multirow{5}{*}{0.6149} \\
\hline $6-10$ years & 6 & 2 & 8 & & \\
\hline $11-15$ years & 5 & 0 & 5 & & \\
\hline $16-20$ years & 1 & 0 & 1 & & \\
\hline $\begin{array}{l}\text { Total } \\
\text { Gender }\end{array}$ & 15 & 3 & 18 & & \\
\hline Male & 6 & 0 & 6 & \multirow{3}{*}{0.450} & \multirow{3}{*}{0.5023} \\
\hline Female & 9 & 3 & 12 & & \\
\hline Total & 15 & 3 & 18 & & \\
\hline
\end{tabular}

\section{The Management of Osteogenesis Imperfecta at Zambia Italian Orthopaedic Hospital Between the 2007 - 2011 Period}

Although $11 \% \quad(\mathrm{n}=2) \quad$ were initially managed conservatively, all patients $100 \% \quad(n=18)$ received Physiotherapy treatment and underwent at least one or more surgeries in their lifetime. In addition, there was no long term drug recorded in any of the patient files.

\section{Discussion}

While, the United States of America Census Bureau [10] reports that there are no exact statistics for the prevalence of OI worldwide some studies have reported the prevalence of 
OI though, mostly low. Viljoen and Beighton [11] reported a higher proportion of type III and type II OI prevalence among the Shona and Ndebele compared to other tribes of Zimbabwe; Samuel and Varghese [12] in Oman reported a fairly large prevalence of OA compared to world-wide estimates of approximately 1 in 20,000 individuals [1]. We recorded a low prevalence of OI in this study $(0.22 \%)$ with majority of the patients having a mean age distribution of 8.67 years implying that most of the affected patients were below the age of 10 . These outcomes are similar to the findings of Samuel \& Varghese [12] who also reported a mean age distribution of 6.46 years. Newacheck [2] echoes that OI has no gender preference; it affects males and female equally among races. In contrast, there were more females (67\%) than males in our study.

According to Engelbert et al [13] OI is potentially incapacitating. We recorded deformities of different kinds among 15 out of the 18 patients. The most frequently affected body parts were the lower limbs with bowed legs followed by the vertebral spine with scoliosis. These results are similar to the reported outcomes in previous studies $[14,15]$. It was observed that in OI cases deformities in the lower limbs were more frequent than in upper limbs. Benson et al [16] also submitted that the incidence and severity of the scoliosis was related to the age of the patient. Furthermore, between the ages of 1 and 5 years, the incidence of scoliosis was $26 \%$ and thereafter it rose steeply to approximately $80 \%$ in patients aged above 12 years. In another study, Moorefield and Miller [17] identified scoliosis in $50 \%$ of their participants aged 31 and above. However, in our study, there were no significant associations between deformities and age $(\mathrm{P}=0.615)$ or deformities and gender $(\mathrm{P}=0.18)$.

Marini et al [3] emphasizes that surgery plays a major role in the management of OI. Further, appropriate goals for surgery include correction of bowing to enhance ambulation potential and to interrupt the cycle of fracture and re-fracture. However, Falk [9] documents that combined therapy is very beneficial to patients with OI. This is in line with Kaur et al [15] who amplify their combined management experience in the correction of lower limb deformities in four children with OI whose medical management consisted of pre- and postoperative bisphosphonate therapy pamidronate in particular, calcium supplementation and rehabilitative care. Deformities were corrected with multiple osteotomies and intramedullary fixation by titanium elastic nails. At 30 months mean followup period all children had significantly improved their ambulatory status; reduced fracture incidences and there was no evidence of recurrence of deformities thereby emphasizing the importance of combined medical and surgical therapy for these patients. At the ZIOH-CBR, surgery was the main treatment method used to manage OI in combination with Physiotherapy. Solfield osteotomies and rodding were the frequently used procedures among the patients. We did not observe any long-term plan on pharmacological products such as anti-biotic or pain relievers. As earlier indicated all, the identified cases in the study had at least one or more surgeries in their lifetime, mostly done to correct deformities and manage fractures.

\section{Conclusion}

In the extrapolation study [10], it was estimated that 1102 cases of OI are diagnosed in Zambia each year. Newacheck [4] commenting on the US Census [10] reported that the report overlooked the geographical aspects and the social economic status of Zambia, hence, the estimated figure did not give the true picture of OI cases in the country. Thus, it can be concluded from this study that $\mathrm{OI}$ is a rare condition, but when present, it can be very disabling and expensive to manage. Surgery is the main treatment method for OI at the ZIOH-CBR. From this study, it was observed that the CBR project of ZIOH only managed patients with OI who were below 18 years of age. While surgery was done on every patient with OI there were no records to determine well established physiotherapy programmes for these patients an aspect this study strongly recommends. A follow up study will also be necessary to determine the plight of these OI patients over a longer period so as to mitigate disability.

\section{Acknowledgements}

This work arose from the research project that was part of the academic requirements for the Bachelor of Physiotherapy degree at the University of Zambia. We thank management of the Zambia Italian Orthopaedics Hospital and the Department of Physiotherapy for having contributed in the success of this study.

\section{References}

[1] Zeitlin L, Fassier F, Glorieux FH (2003). Modern approach to children with osteogenesis imperfecta.; $J$ Pediatr Orthop B.12(2):77-87

[2] Newacheck PW (2007). An epidemiologic profile of children with special health care needs. paediatrics 102(1); 117-123.

[3] Marini JC (2007). Osteogenesis imperfecta. In: Kliegman RM, Behrman RE, Jenson HB, Stanton BF, ds. Nelson Textbook of Pediatrics. 18th ed. Philadelphia, Pa: Saunders Elsevier; chap 699.

[4] Newacheck PW, Halfon W (1998). An epidemiologic profile of children with special health care needs. American Journal of Public Health, April 88(4):610-17.

[5] Marini JC, Fines H (2007). Osteogenesis imperfecta: comprehensive management. Adv Pediatr 35:391- 426.

[6] Cheung MS, Glorieux FH (2008). Osteogenesis Imperfecta: update on presentation and management. Rev Endocr Metab Disord 9, 153-160.

[7] Wilson D (2007). Wong's essentials of pediatric nursing. $7^{\text {th }}$ edition. Elsevier, Mosby.

[8] Marini JC, Cabral WA, Barnes AM (2010). Null mutations in LEPRE1 and CRTAP cause severe recessive osteogenesis imperfecta. Cell and tissue research 339, 59-70. 
[9] Falk MJ (2003). Intravenous biphosphonate therapy in children with osteogenesis imperfect. Paediatrics, 111(3): 573578.

[10] US Census Bureau, International Data Base (2004). http://gsociology.icaap.org/reports.html [Accessed April 23, 2012]

[11] Viljoen D, Beighton P (2011). "Osteogenesis imperfecta type III: an ancient mutation in Africa?" Am. J. Med. Genet. 27 (4): 907-12. doi: 10.1002/ajmg.1320270417. PMID 3425600

[12] Samuel CJ, Varghese TP (2007). A Retrospective study of Osteogenesis imperfecta in Dakhliya region. Orthopaedics department, Nizwa Hospital Middle East.

[13] Engelbert RHH, Uiterwaal CS, Grever WJ, Pruijs HE, Helders PJ (2004). Osteogenesis imperfecta in childhood: impairment and disability. A prospective study with 4-year follow-up. Arch Phys Med Rehabil. 85, 772-8.

[14] Amako M, Fassier F, Hamdy RC, Aarabi M, Montpetit K, Glorieux FH (2004). Functional analysis of upper limb deformities in osteogenesis imperfecta. J Pediatr Orthop 24, 689-694.

[15] Kaur S, Kulkarna Kp, Kochar Is, Narasimhan R (2011). Management of Lower Limb Deformities in Children with Osteogenesis Imperfecta, New Delhi, India.

[16] Benson DR, Donaldson DH, Millar EA (2000). The spine in osteogenesis imperfecta. J Bone Joint Surg [Am] 60-A: 925-9

[17] Moorefield WG, Miller GR (2008). Aftermath of osteogenesis imperfecta: the disease in adulthood. $J$ Bone Joint Surg, 62(1):13-19. 